\title{
FAKTOR FAKTOR YANG MEMPENGARUHI KEBERHASILAN IBU BEKERJA DALAM PEMBERIAN ASI EKSKLUSIF
}

\section{THE INFLUENCE FACTORS AFFECT EXCLUSIVE BREASTFEEDING SUCCESFULL OF WORKING MOTHER}

\author{
Rizki Amalia*, Lailatul Khusnul Rizki \\ Fakultas Keperawatan dan Kebidanan, Universitas Nahdlatul Ulama, Surabaya
}

\begin{abstract}
ABSTRAK
Air susu ibu (ASI) merupakan makanan bayi yang terbaik. ASI tidak dapat digantikan oleh makanan atau minuman apapun walaupun ibu dalam keadaan bekerja di luar rumah, faktor faktor yang mempengaruhi keberhasilan pemberian ASI eksklusif pada ibu bekerja adalah sikap ibu bekerja, dukungan sarana, atasan dan suami. Tujuan penelitian ini adalah untuk mengetahui hubungan sikap, dukungan sarana, atasan dan suami terhadap keberhasilan ibu menyusui pada ibu bekerja. Metode penelitian yang digunakan yaitu deskriptif analitik dengan pendekatan cross sectional. Populasi dan sampel penelitian adalah ibu menyusui yang bekerja, menggunakan total sampling. Pengumpulan data dilakukan secara langsung menggunakan kuesioner tertutup dan dianalisis menggunakan uji Chi square dengan taraf kesalahan 0,05. Hasil penelitian didapatkan sikap ibu bekerja, dukungan sarana, atasan dan suami berpengaruh terhadap keberhasilan pemberian asi eksklusif oleh ibu bekerja ( $\mathrm{p}<0,05)$. Kesimpulan penelitian ini menunjukkan hubungan yang signifikan antara keberhasilan pemberian asi eksklusif dengan sikap ibu, dukungan sarana, atasan dan suami.
\end{abstract}

Kata kunci : air susu ibu (ASI), asi eksklusif, ibu bekerja

\section{ABSTRACT}

Breast Milk is the best baby food. Breast milk can not be replaced by any other food or drink even if the mother is working outside the home. The factors that influence the success of exclusive breastfeeding in working mother are the attitude of mother, the support of the facilities, supervisor and husband. The aim of the study was to investigate the relationship of attitude, support facilities, supervisor and husband to the success of exclusive breastfeeding of working mother. The analytical descriptive with cross sectional approach was used in this study. The population and sample of the study were working mothers, with total sampling. Data collection was done directly through closed questionnaire and analyzed by Chi square test with error level 0,05. The result of this study was the attitude of working mother, support of facilities, supervisor and husband influence the succesfull of exclusive breastfeeding of working mother $(\mathrm{p}<0,05)$. The conclusion of the study was exclusive breastfeeding correlated to mother's attitude, support facilities, supervisor and husband significantly. Keyword: ASI, exclusive breastfeeding, working mother

*Corresponding author:

Rizki Amalia

Fakultas Keperawatan dan Kebidanan, Universitas Nahdlatul Ulama, Surabaya

Email: Amalia24@unusa.ac.id 


\section{PENDAHULUAN}

Air Susu Ibu (ASI) merupakan makanan terbaik untuk bayi. ASI tidak dapat digantikan oleh makanan atau minuman lain disaat ibu dalam keadaan bekerja di luar rumah. Faktor-faktor yang mempengaruhi keberhasilan pemberian ASI eksklusif pada ibu bekerja antara lain sikap ibu bekerja, dukungan sarana, atasan dan suami.

Sikap ibu bekerja yang aktif melakukan kegiatan komersial seperti bekerja di kantor atau pabrik, menjalankan usaha pribadi sebagai tambahan penghasilan memilih menggunakan susu formula karena dianggap lebih menguntungkan (Bai,et al., 2010). Terlebih lagi dengan adanya iklan di berbagai media mempengaruhi sikap ibu dalam hal pemilihan susu formula sebagai pengganti ASI eksklusif (Prasetyono, 2012). Faktor lain yang mempengaruhi sikap ibu dalam pemberian ASI eksklusif adalah terlalu singkatnya waktu cuti melahirkan (Dearden, et al., 2002).

Menyusui dapat dilakukan baik secara langsung maupun tidak langsung. Menyusui secara tidak langsung dilakukan dengan memberikan ASI perah dalam kondisi segar maupun tersimpan. Beberapa perusahaan ada yang sudah menyediakan ruang laktasi dengan segala perlengkapannya berupa lemari pendingin, apron, air hangat, bantal menyusui (Bai, et al., 2002; Depkes, 2006). Namun, beberapa diantaranya ada yang membatasi hingga saat ini masih banyak pekerja perempuan yang tidak dapat melaksanakan haknya untuk memberikan ASI selama bekerja (AIMI, 2012; Basrowi, 2012).

Berdasarkan hasil Survei Sosial Ekonomi Nasional (Susenas) tahun 2004-2009, cakupan pemberian ASI eksklusif pada seluruh bayi dibawah 6 bulan meningkat dari 58,9\% pada tahun 2004 menjadi $61,3 \%$ pada tahun 2009. Begitu juga dengan cakupan bayi yang mendapat ASI eksklusif terus menerus dari usia 0 sampai 6 bulan juga meningkat dari 19,5\% tahun 2005 menjadi 34.3\% pada tahun 2009. Meskipun terdapat kenaikan cakupan, namun cakupan ini belum memenuhi target. Berdasarkan studi pendahuluan didapatkan data bahwa sebanyak $85 \%$ bayi tidak mendapatkan ASI eksklusif.

\section{METODE PENELITIAN}

Metode penelitian menggunakan deskriptif analitik dengan pendekatan cross sectional. Populasi dan sampel penelitian adalah ibu menyusui yang bekerja, menggunakan total sampling. Penelitian dilakukan di RW 02 Karah, Jambangan, Surabaya.

\section{Alat dan Bahan}

Alat dan bahan yang digunakan yaitu kuesioner tertutup berisi 8 pertanyaan untuk sikap dan 3 pertanyaan untuk dukungan sarana, atasan, dan suami.

\section{Jalannya Penelitian}

Ijin penelitian diperoleh dari LPPM Universitas Nahdatul Ulama, Surabaya. Tenaga pembantu penelitian adalah ketua RW 02 Karah, Jambangan, Surabaya dan kader kesehatan. Sampel adalah ibu bekerja yang mempunyai anak usia 0-2 tahun. Alat ukur berupa kuesioner tertutup diberikan kepada seluruh responden yang berjumlah 30 orang dengan pemberian informed consent sebelumnya.

\section{Analisis Data}

Analisis univariat berupa distribusi frekuensi karakteristik responden dinyatakan dalam tabel. Analisis bivaria dan multivariat untuk menguji hubungan antara masing-masing variabel. 


\section{HASIL DAN PEMBAHASAN}

Tabel I. Sikap ibu bekerja

Distribusi frekuensi responden menurut sikap

\begin{tabular}{llcc}
\hline No & \multicolumn{1}{c}{ Sikap } & Frekuensi & Persentase (\%) \\
\hline 1. & KurangBaik & 12 & 40,0 \\
2. & Baik & 18 & 60,0 \\
\hline \multicolumn{2}{r}{ Jumlah } & 30 & 100 \\
\hline
\end{tabular}

Sumber : Data primer terolah 2017

Tabel II. Dukungan suami

Distribusi frekuensi responden menurut dukungan suami

\begin{tabular}{lccc}
\hline No & Dukungan suami & Frekuensi & Persentase (\%) \\
\hline 1. & Tidak mendukung & 17 & 56,7 \\
2. & Mendukung & 13 & 43,3 \\
\hline Jumlah & 30 & 100 \\
\hline
\end{tabular}

Sumber : Data primer terolah 2017

Tabel III. Dukungan atasan

\begin{tabular}{llcc}
\hline No & Dukungan atasan & Frekuensi & Persentase $(\boldsymbol{\%})$ \\
\hline 1. & Tidak mendukung & 18 & 60 \\
2. & Mendukung & 12 & 40 \\
\hline Jumlah & 30 & 100 \\
\hline
\end{tabular}

Sumber : Data primer terolah 2017

Tabel IV. Dukungan sarana dan prasarana

\begin{tabular}{llcc}
\hline No & Saranadanprasana & Frekuensi & Persentase (\%) \\
\hline 1. & Tidak ada & 16 & 53,3 \\
2. & Ada ruang laktasi & 14 & 46,7 \\
\hline Jumlah & 30 & 100 \\
\hline
\end{tabular}

Sumber : Data primer terolah 2017

Tabel V. Hubungan sikap dengan pemberian ASI

\begin{tabular}{|c|c|c|c|c|c|c|}
\hline \multicolumn{7}{|c|}{ ASI Eksklusif } \\
\hline & \multicolumn{2}{|r|}{ berhasil } & \multicolumn{2}{|r|}{ Tdk } & \multicolumn{2}{|r|}{ Jumlah } \\
\hline & $\mathbf{N}$ & Prosentase & $\mathbf{N}$ & Prosentase & $\mathbf{N}$ & Prosentase \\
\hline Baik & 9 & 30 & 3 & 10 & 12 & 40 \\
\hline $\begin{array}{l}\text { Kurang } \\
\text { baik }\end{array}$ & 8 & 26,67 & 10 & 33,33 & 18 & 60 \\
\hline Jumlah & 17 & 56,67 & 13 & 43,33 & 30 & 100 \\
\hline
\end{tabular}

Sumber : Data primer terolah 2017

Mandala of Health : A Scientific Journal Vol.11, No.1, Maret 2018, Hal. 44-50 
Hasil penelitian menunjukkan bahwa ada hubungan antara sikap ibu dengan pemberian ASI eksklusif dengan nilai $\mathrm{p}=0,021$. Hal ini terjadi karena responden setuju mengenai ASI merupakan makanan yang lengkap zat gizinya. Memberikan ASI eksklusif dapat menyebabkan pertumbuhan yang baik pada bayi (berat badan bayi naik sesuai umur). Memberikan ASI dapat mempererat hubungan batin antara ibu dengan bayi. Pemberian ASI eksklusif dapat menghemat biaya pengeluaran keluarga.

Tabel VI. Dukungan suami dengan ASI

\begin{tabular}{lllllll}
\hline & \multicolumn{5}{c}{ ASI Eksklusif } \\
& & \multicolumn{2}{c}{ berhasil } & \multicolumn{2}{c}{ Tdk } & Jumlah \\
\cline { 2 - 8 } & N & Prosentase & N & Prosentase & N & Prosentase \\
\hline Mendukung & 12 & 40 & 1 & 3.33 & 13 & 43.33 \\
\hline $\begin{array}{l}\text { Tidak } \\
\text { mendukung }\end{array}$ & 5 & 16.67 & 12 & 40 & 17 & 56.67 \\
\hline Jumlah & 17 & 56.67 & 13 & 43.33 & 30 & 100 \\
\hline
\end{tabular}

Sumber : Data primer terolah 2017

Penelitian terdahulu yang dilakukan oleh Ramadani (2010) menyatakan bahwa terdapat hubungan antara dukungan suami dengan pemberian ASI eksklusif pada ibu di puskesmas. Hubungan ini memiliki nilai $\mathrm{p}=0,008$ berarti $\mathrm{p}$-value $<0,05$ sehingga berdasarkan uji statistik variabel berhubungan. Ibu dengan dukungan suami sedang berpeluang 1,8 kali lebih besar dibandingkan dengan dukungan suami rendah. Ibu yang memiliki dukungan suami baik berpeluang 4,95 kali memberikan ASI eksklusif dibandingkan ibu dengan dukungan suami rendah.

Dukungan suami sangat berpengaruh terhadap keberhasilan pemberian ASI esklusif. Massa, et al. (2014) menyatakan bahwa terdapat dua kategori yang berpengaruh terhadap keberhasilan pemberian ASI ekslusif, salah satu diantaranya adalah pengaruh sosial primer yaitu dukungan orangorang terdekat. Dukungan suami dapat meningkatkan rasa percaya diri pada ibu menyusui. Produksi ASI juga meningkat karena perasaan nyaman yang dialami oleh ibu yang mendapat dukungan suami. Reeves, et al. (2012) juga menyatakan bahwa perasaan tenang, tentrak dan nyaman yang dirasakan oleh ibu menyusui dapat meningkatkan produksi hormone oksitosin. Ibu menyusui yang mendapatkan dukungan dari anggota keluarga, terutama suami atau pasangan dan kakek-nenek, berpengaruh positif terhadap kepercayaan diri ibu menyusui. Anggota keluarga harus mendukung ibu dan membantu ibu dalam hal pemberian ASI sehingga ibu merasa mampu dan didukung untuk menyusui. 
Tabel VII. Dukungan atasan dengan ASI

\begin{tabular}{lllllll}
\hline & \multicolumn{5}{c}{ ASI Eksklusif } \\
& \multicolumn{3}{c}{ berhasil } & \multicolumn{2}{c}{ Tdk } & Jumlah \\
\cline { 2 - 7 } & N & Prosentase & N & Prosentase & N & Prosentase \\
\hline Mendukung & 10 & 33,33 & 2 & 6,67 & 12 & 40 \\
\hline $\begin{array}{l}\text { Tidak } \\
\text { mendukung }\end{array}$ & 7 & 23,34 & 11 & 36,66 & 18 & 60 \\
\hline Jumlah & 17 & 56.67 & 13 & 43.33 & 30 & 100
\end{tabular}

Sumber : Data primer terolah 2017

Hasil penelitian ini menyatakan bahwa ada hubungan yang signifikan antara dukungan atasan dengan keberhasilan pemberian ASI eksklusif dengan nilai $p=0,042$. Hal ini sesuai dengan teori yang menyatakan persaingan pasar semakin ketat, masih banyak dijumpai wanita pekerja belum mendapatkan hak menyusui. Keberhasilan menyusui bagi ibu bekerja di tempat bekerja sangat dipengaruhi oleh lingkungan yang dibangun oleh perusahaan, pimpinan perusahaan termasuk di dalamnya (Payne and Nicholls, 2009).

Lingkungan kerja merupakan lingkungan sosial yang berperangaruh terhadap keberhasilan pemberian ASI eksklusif bagi ibu bekerja. Lingkungan kerja dapat memberikan dukungan dalam bentuk dukungan dari rekan kerja, supervisor, tersedianya tempat menyusui atau memerah ASI dan dukungan penuh dari pimpinan atau pemilik perusahaan. Pimpinan memegang peran penting dalam keberhasilan menyusui di tempat kerja (Glenn, 2008). Pimpinan yang mempunyai pengetahuan dan kemampuan yang baik dalam mempertimbangkan pemberian biaya yang tinggi saat penerimaan dan pemberian training pada karyawan, pimpinan akan berkeinginan untuk melakukan negosiasi kepada ibu bekerja yang akan menyusui. Sebaliknya Pimpinan perusahaan/institusi yang mempunyai pengalaman atau pengetahuan tentang ASI eksklusif akan mempertimbangkan kebutuhan dan harapan ibu bekerja di perusahaannya. Kebutuhan dan harapan pimpinan terhadap produktivitas dan kualitas ibu bekerja sangat besar karena mempengaruhi hasil dan biaya produksi yang harus dikeluarkan oleh perusahaan (Gatrel, 2007).

Tabel VIII. Dukungan sarana

\begin{tabular}{lllllll}
\hline & & \multicolumn{5}{c}{ ASI Eksklusif } \\
& & berhasil & & Tdk & & Jumlah \\
\cline { 2 - 7 } & N & Prosentase & N & Prosentase & N & Prosentase \\
\hline Mendukung & 12 & 40 & 2 & 6,67 & 14 & 43.33 \\
\hline $\begin{array}{l}\text { Tidak } \\
\text { mendukung }\end{array}$ & 5 & 16.67 & 11 & 36,66 & 16 & 56.67 \\
\hline Jumlah & 17 & 56.67 & 13 & 43.33 & 30 & 100 \\
\hline
\end{tabular}

Sumber : Data primer terolah 2017

Mandala of Health : A Scientific Journal Vol.11, No.1, Maret 2018, Hal. 44-50 
Berdasarkaaun hasil penelitian didapatkan bahwa ada hubungan yang signifikan antara dukungan sarana dengan keberhasilan pemberian ASI eksklusif dengan nilai $p=0,008$. Ketersediaan sarana dan prasarana pendukung untuk memberikan ASI eksklusif berupa ASI perah bagi ibu bekerja sangat menunjang keberhasilan pemberian ASI eksklusif. Meskipun demikian, masih terdapat ibu bekerja yang lebih memilih memberikan susu formula dengan alasan kepraktisan dalam penyimpanan maupun pemberiannya. Tersedianya fasilitas berupa ruang laktasi merupakan faktor yang sangat penting dalam mendukung keberhasilan pemberian ASI eksklusif. Ruki (2011) menyatakan bahwa keberadaan sebuah ruang ibu dan anak serta ruang laktasi tidak hanya menjadi penunjang keberhasilan pemberian ASI ekslusif namun jug adapt menjadi motvasi atua pendorong bagi ibu untuk tetap melanjutkan pemberia ASI eksklusif. Keberadaan ruang laktasi merupakan kebijakan pemerintah untuk menjamin pemenuhan hak bayi mendaptkan ASI ekslusif.

\section{KESIMPULAN}

Terdapat hubungan yanga signifikan antara sikap ibu bekerja dengan keberhasilan pemberian ASI eksklusif. Terdapat hubungan yang signifikan antara dukungan suami terhadap keberhasilan pemberian ASI eksklusif. Terdapat hubungan yang signifikan antara dukungan atasan terhadap keberhasilan pemberian ASI eksklusif. Terdapat hubungan yang signifikan antara dukungan sarana terhadap keberhasilan pemberian ASI eksklusif.

\section{UCAPAN TERIMAKASIH}

Penulis mengucapkan terimakasih kepada semua responden, kader kesehatan, ketua RW kelurahan Karah, Jambangan, Surabaya.

\section{DAFTAR PUSTAKA}

Aisyaroh, N \& Sutrisminah, E. 2017. Evaluasi fasilitas ruang ASI dalam implementasi kebijakan pemberian ASI eksklusif pada buruh perempuan di perusaah ekstil Jawa Tengah. Prosiding Seminar Nasional Publikasi Hasil-Hasil Penelitian dan Pengabdian Masyarakat "Implementasi Penelitian dan Pengabdian Masyarakat Untuk Peningkatan Kekayaan Intelektual. Universitas Muhammadiyah. Semarang, 30 September 2017.

Asosiasi Ibu Menyusui Indonesia (AIMI). 2012. Lingkungan kerja ramah laktasi, pedoman untuk perusahaan

Azisya S. 2010. Sukses menyusui meskipun bekerja. Gema Insani Press. Jakarta.

Basrowi, R. 2012. Pemberian ASI eksklusif pada perempuan pekerja sektor formal. Tesis. Fakultas Kedokteran, Universitas Indonesia.

Bai, Y.K. Middlestadt, S.E. Joanne Peng, C.Y. Fly, A.D. 2010. Predictors of continuation of exclusive breastfeeding for the fi rst six months of life. Journal Human Lactation 26(1): 26-34.

Bai, Y.K. Middlestadt, S.E. Joanne Peng, C.Y. Fly, A.D. 2002. Psychosocial factors underlying the mother's decision to continue exclusive breastfeeding for 6 months: an elicitation study. $J$ Hum Nutr Diet 22: 134-40. 
Depkes RI. 2006. Kebijaksanaan departemen kesehatan tentang peningkatan pemberian air susu ibu (ASI) pekerja wanita. Pusat Kesehatan Kerja.

Dearden, K.A. Quan le, N. Do, M. Marsh, D.R. Pachon, H. Schroeder, D.G. et al. 2002. Work outside the home is the primary barrier to exclusive breastfeeding in rural Vietnam:insights from mothers who exclusively breastfed and worked. Food and Nutrition Bulletin 23 Suppl 4: 1018.

Gatrell, C.J. 2007. Secrets and lies: breastfeeding and professional paid work. Social Sciences and Medicine 65: 393-404.

Glenn, J.S. 2008. Knowledge, perceptions, and attitudes of managers, coworkers, and employed breastfeeding mothers. American Association of Occupational Health Nurses Journal 56(10): 423-31.

Kusumayanti, N., Nindya, T.S. 2017. Hubungan dukungan suami dengan pemberian asi eksklusif di daerah perdesaan. Media Gizi Indonesia 12 (2): 98-106.

Mazza, V.D.A., Regina, C.T.N., \& Rafaela, Z.P.T. 2014. Infl uence of social support networks for adolescent breastfeeding mother in the process of breastfeeding. International Breastfeeding Journal 19: 1-7.

Payne, D. And Nicholls, D.A. 2009. Managing breastfeeding and work: a Foucauldian secondary analysis. Journal of Advanced Nursing 66(8): 1810-18.

Reeves., C., Close, F.T., Simmons, M.C., \& Hollis, A.L. 2012. Social support indicators that infl uence breastfeeding decision in mothers of north florida. Florida Public Health Review 3: 17. 